\author{
A. Neftisov \\ $\mathrm{PhD}$, Director of the Science and Innovation Center "Industry 4.0", \\ alexandr.neftissov@astanait.edu.kz,orcid.org/0000-0003-4079-2025 \\ Astana IT University, Kazakhstan \\ O. Talipov \\ PhD, Associated professor of the Department of Heat Power Engineering \\ talipov1980@mail.ru, orcid.org/0000-0002-8355-1769 \\ Toraigyrov University, Kazakhstan

\section{O. Andreeva} \\ PhD., Associated professor of the Department of Electrical Engineering \\ and Automation \\ andreyeva.oa@mail.ru,orcid.org/0000-0001-8680-5712 \\ Toraigyrov University, Kazakhstan
}

\title{
DEVICE FOR DETERMINING THE VALUE OF THE STEADY-STATE ELECTRICITY IN THE PRIMARY CIRCUIT USING A REED SWITCH AND A MICROPROCESSOR
}

\begin{abstract}
This article discusses an innovative device designed to determine the value of the steady-state current in the primary circuit of electrical installations using reed switches and a microprocessor without the use of current transformers. The typical structure of relay protection devices is considered. The main elements are presented.

When choosing a primary converter, a reed switch was taken, because it has certain advantages over current transformers. As part of the research, experimental installations for measurements were assembled. They made it possible to emulate the real conditions in which the relay protection devices have to function, unnecessary and to depict the characteristics of future devices.

The code is presented that allows the microprocessor device to function according to the laid down algorithm. A device on a reed switch and a microprocessor is presented, which allows transmitting a certain amount of current in the primary circuit in digital form (binary code) to the microprocessor protection. The presented measuring device made it possible to implement a method for determining the magnitude of the steady-state short-circuit current.

Keywords: Relay protection, reed switch, microprocessor, identification, current transformer, short circuit.
\end{abstract}

\section{Introduction}

Relay protection devices (RP), designed to detect and disable faults on electrical installations, have a typical structure in accordance with Figure 1, which is divided into measuring (MP), logical (LP) and control (CP) parts. The MP is responsible for the state of the protected electrical installation and issues a signal to the LP when damage occurs. LP receiving a signal from the MP, it executes its logic program and sends a signal to the MP, which is necessary to actuate the switch, etc., amplifying the signal from the LP. Current information is traditionally obtained using current transformers (TC) [1]. 


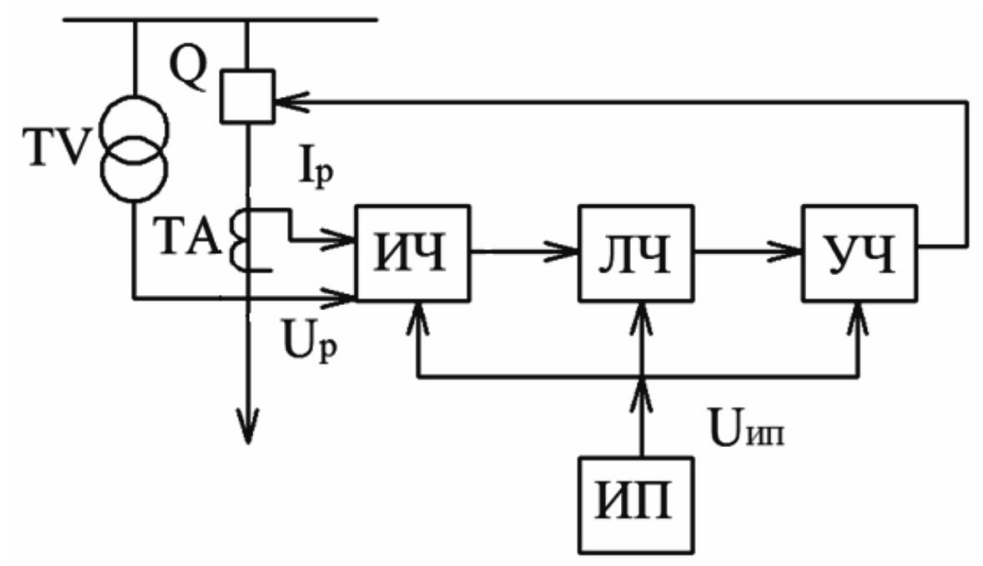

Fig. 1. Typical structure of relay protection devices

At the same time, work is underway [2-5] on the use of magnetosensitive elements for relay protection without TA, which, in turn, are very metal-consuming, distort information when the cores are saturated and create high voltages in secondary circuits when they are broken. As noted at the International Conference on Large Energy Systems (CIGRE) [6], because of these shortcomings, such work is currently relevant. Now it is difficult to give preference to any solution, since most of the work is still far from completion. Relay protection on magnetically sensitive contacts (MK) - reed switches [5-9], which are widely used in technology [10, $11]$, has development prospects [11, 12]. Some important advantages for RE over other magnetosensitive elements are described in [7-9]. One of the key points is the way to identify the current curve using a reed switch and a microprocessor.

According to the chosen method [13], information about the current in the conductor can be obtained using a reed switch. To determine the magnitude of the steady-state AC shortcircuit current, the microprocessor performs the following operations: time measurement $t_{1}$ closed state of the reed switch; definition $I_{m}$ according to the previously entered formula - the approximated dependence $I_{m}=K_{\Pi P} \cdot I_{m K}^{K}=K_{\Pi P} \cdot f\left(t_{1}^{K}\right)$, which was taken in the laboratory using $\mathrm{Cl}$. The microprocessor allows you to add a software block for comparing a certain current value with the pickup setting. And when the output relay is connected and the setpoint is exceeded, a signal can be sent to it. When measuring the time of the closed state of the reed switch contacts, as is known $[13,14]$, an accuracy of $1 \mu \mathrm{s}$ is required to reduce the errors in determining the magnitude of the current.

For an experimental study of the device on a reed switch and a microprocessor, an installation with a conductor was assembled in accordance with Figure 2. 


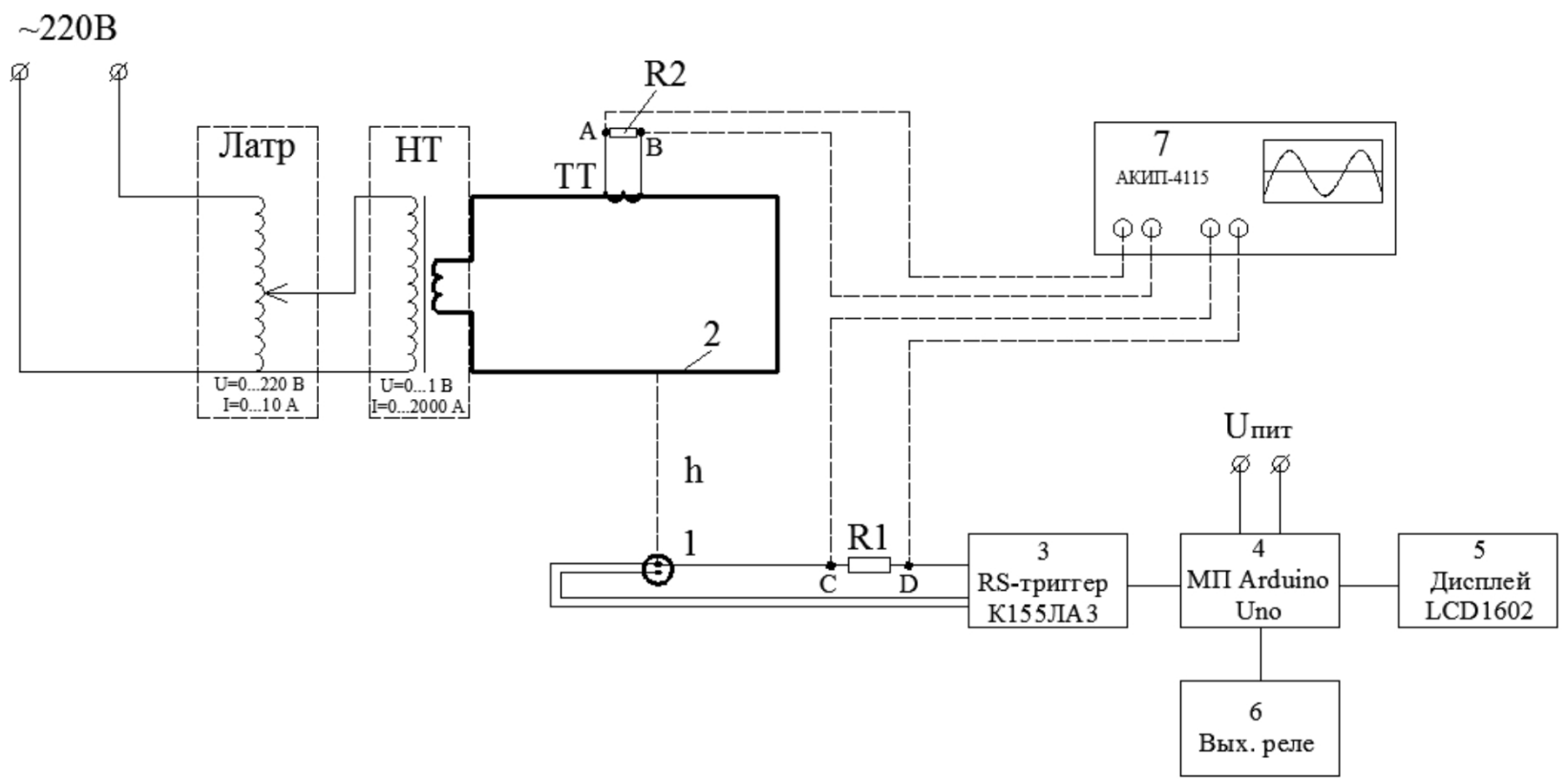

Fig. 2. Installation for creating short-circuit currents

In the installation, an autotransformer (LATR) RNO-250-10 [15] is connected to the 220V supply network, with the help of which the value of the flowing current in the conductor 2 was regulated. which serves as a load transformer. The current lead 2 is connected to the wound winding on a toroidal CT. The winding is made of 8 turns of a cable with a cross section of $95 \mathrm{~mm} 2$ connected in parallel. In this setup, an alternating current of up to $2000 \mathrm{~A}$ was passed through conductor 2 . Reed switch 1 was located at a safe distance $\mathrm{h}$ from conductor 2. All measurements were monitored using an AKIP-4115 digital oscilloscope. One probe was connected to a low-impedance resistor R1, which was connected in series between the reed switch 1 and the anti-bounce circuit 3, and the second probe was connected to a lowimpedance resistor R2 connected to the output of the secondary winding of the measuring current transformer TT (TTE125-4000 / 5A, accuracy class 0.5) through the window of which the conductor 2 passes. The following elements belong to the device. Reed switch 1, the contacts of which are connected to anti-bounce circuit 3, which is made on the RS flipflop. It is assembled on the basis of the common K155LA3 microcircuit. The signal about actuation and dropout from anti-bounce circuit 3 is fed to the discrete input of the connected microprocessor 4. As microprocessor 4, an Arduino Uno board based on ATMega 328p is taken. When the reed switch contacts bounce, the microprocessor manages to measure the duration of the arising pulses, which leads to false results. To avoid this, circuit 3 is used. The microprocessor is powered from a $5 \mathrm{~V}$ constant voltage source. By means of a loop, a display 5 LCD1602 is connected to the microprocessor 4 to display information about the determined value of the steady-state current. The block implemented in software additionally compares a certain value with a setpoint. When it is exceeded, a signal is sent to the output relay 6 , which is connected to the discrete output of the microprocessor 4 . The contacts of the output relay 6 can switch the signal either to the blinker or to the trip coil of the circuit breaker of the protected electrical installation.

On the installation for creating short-circuit currents when the reed switch is located at a safe distance of $100 \mathrm{~mm}$, the multiplicity $\mathrm{K}$ (the ratio of the amplitude of the current to the operating current of the reed switch) does not exceed 3. To study the operation of the device at large multiplicity, the installation was assembled in accordance with Figure 3 using the KI. In the installation, an autotransformer (LATR) $2 \mathrm{M}$ is connected to the 
$220 \mathrm{~V}$ supply network. On the regulated side of the autotransformer, a circuit of two series resistors $\mathrm{R} 2, \mathrm{R} 3$ and an inductor $2 \mathrm{KI}$ (LK > RK) with a reed switch 1 located inside it is connected. The current in KI 2 and the operation of reed switch contacts 1 is monitored using a digital oscilloscope AKIP-4115 [sixteen]. The first probe is connected to resistor R2, which is located between $\mathrm{KI}$ and $\mathrm{R} 3$. The second probe to the resistor R1, which is connected in series in the circuit between the reed switch 1 and anti-bounce laughter 3 . Further, the elements correspond to Figure 2. In a laboratory installation with a $\mathrm{Kl}$, in which a reed switch is located, when a current of $3 \mathrm{~A}$ flows in it, the multiplicity $\mathrm{K}=50$ for KEM-3, and for $\mathrm{KEM}-2 \mathrm{~K}=80$.

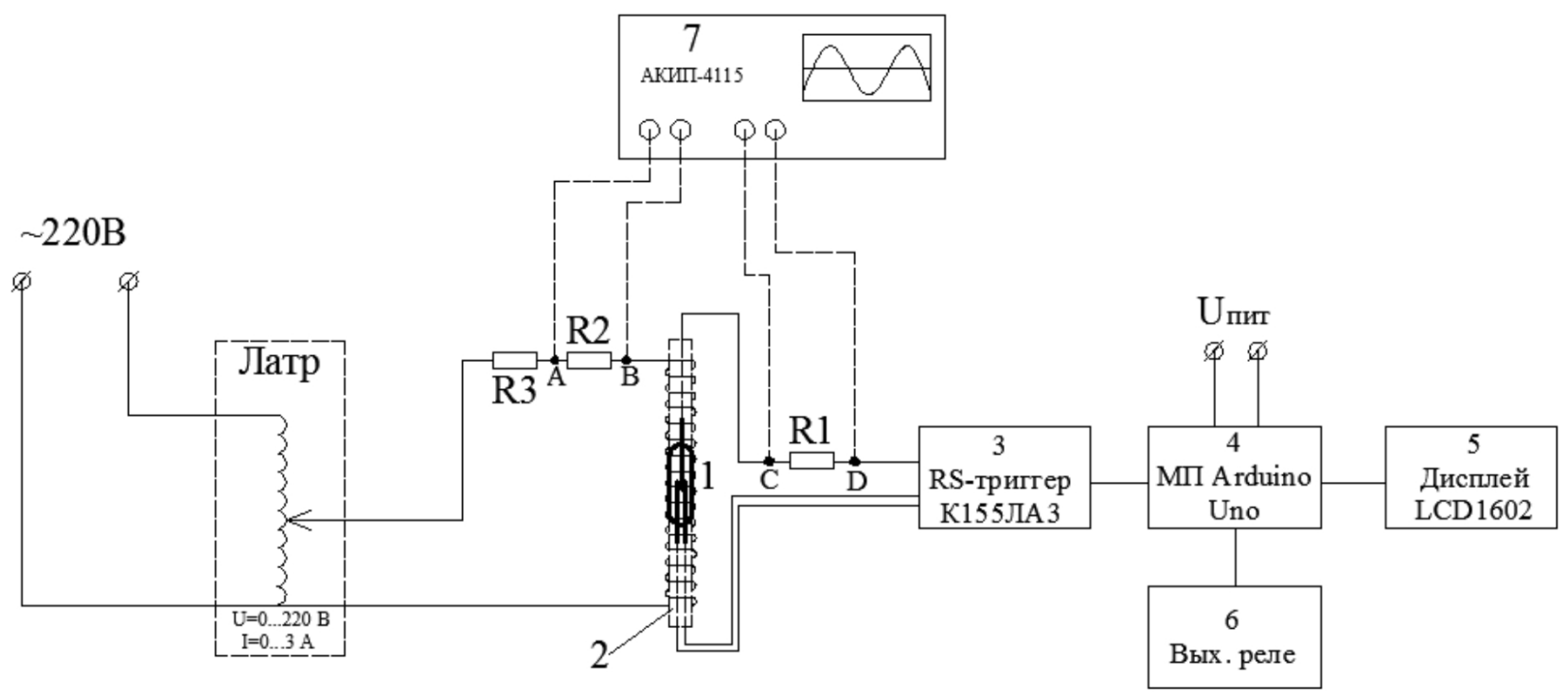

Fig. 3. Installation with KI

The device on a reed switch and a microprocessor, due to the presence of a program unit for comparison with a setting and an output relay, allows to obtain a measuring device for current protection. An experimental model of the measuring device is shown in accordance with Figure 4.

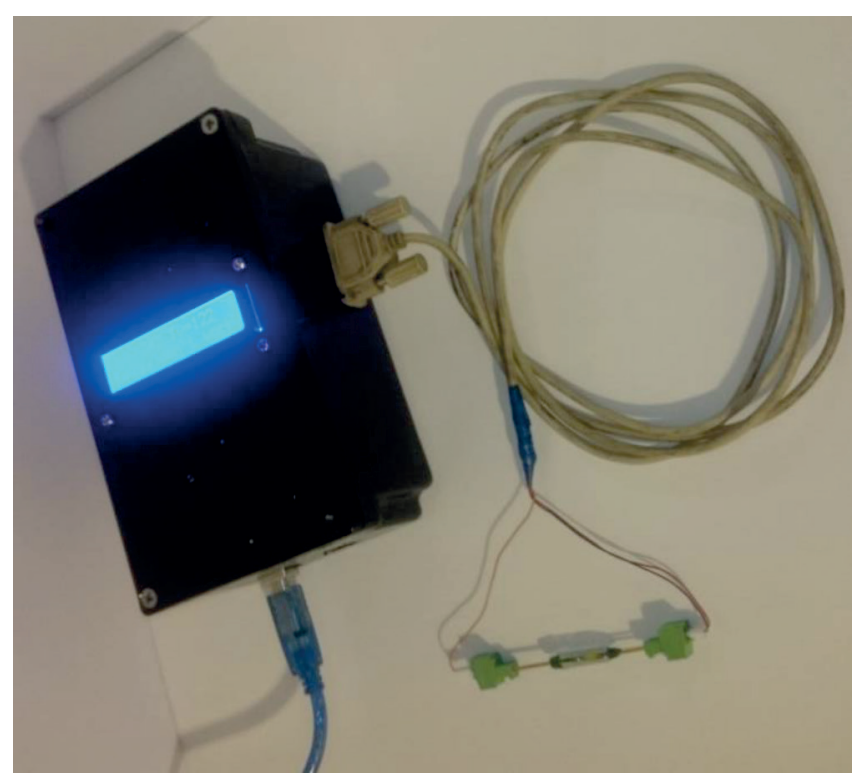

Fig. 4. Photo of the measuring body 
The program that operates in the measuring body is as follows:

unsigned long $\mathrm{t} 1$; // introduce variables

float Im;

float $\mathrm{a} 0=-2,318$;

float $\mathrm{a} 1=3,493$;

float a2=-2,309;

float a3=0,879;

float a $4=-2,128$;

float a $5=3,39$;

float a $6=-3,56$;

float a7=2,376;

float a $8=-9,147$;

float a9=1,549;

\#include<LiquidCrystal.h>// connect the library to work with the display

LiquidCrystal lcd(7, 8, 9, 10, 11, 12);

void setup() \{

pinMode(2, INPUT); // configure ports for reading

pinMode(13, OUTPUT); // configure ports for recording

Serial.begin(9600);

lcd.begin(16, 2);// loading screen

lcd.print(“Loading");

delay(500); / / wait 0.5 seconds

lcd.print(“"”);

delay(500); / / wait 0.5 seconds

lcd.print(".");

delay(500); / / wait 0.5 seconds

lcd.print(".");

delay(1000); // wait 1 seconds

lcd.clear(); / / clearing the screen\}

void loop) \{

$\mathrm{t} 1$ = pulseln $(2, \mathrm{HIGH}) ; / /$ closed time measurement

// determine the current value by measuring time

$\mathrm{Im}=\mathrm{a} 0 \cdot(\operatorname{pow}(10,6))+\mathrm{a} 1 \cdot(\operatorname{pow}(10,3)) \cdot \mathrm{t} 1+\mathrm{a} 2 \cdot(\operatorname{pow}(\mathrm{t} 1,2))+\mathrm{a} 3 \cdot(\operatorname{pow}(10,-3)) \cdot(\operatorname{pow}(\mathrm{t1}, 3))+\mathrm{a} 4 \cdot(\operatorname{pow}$ $(10,-7)) \cdot(\operatorname{pow}(\mathrm{t1}, 4))+\mathrm{a} 5 \cdot(\operatorname{pow}(10,-11)) \cdot(\operatorname{pow}(\mathrm{t} 1,5))+\mathrm{a} 6 \cdot(\operatorname{pow}(10,-15)) \cdot(\operatorname{pow}(\mathrm{t1}, 6))+\mathrm{a} 7 \cdot(\operatorname{pow}(10$, -19)) $\cdot(\operatorname{pow}(\mathrm{t1}, 7))+a 8 \cdot(\operatorname{pow}(10,-24)) \cdot(\operatorname{pow}(\mathrm{t1}, 8))+\mathrm{a} 9 \cdot(\operatorname{pow}(10,-28)) \cdot(\operatorname{pow}(\mathrm{t1}, 9))$;

If $(\mathrm{Im}>500) / /$ output trigger condition

\{

digitalWrite(13, HIGH);// output trigger

\}

else

\{

digitalWrite(13, LOW);// output failure

Serial.println(t1);// we display the value of the closed time. comp. on PC

Serial.println(Im);// display the current value on the PC

// display information on the display

lcd.setCursor $(0,0) ; / /$ set the cursor to the 0th column, 0th row

lcd.print(“"t1=”);

lcd.print(t1);// display the measured time

lcd.setCursor $(0,1) ; / /$ set the cursor in the 0 th column, 1 st row 
lcd.print(“Im=");

lcd.print(Im);// display the current value

\} End of the program.

\section{Characteristics of the current protection measuring device.}

The performance is estimated from the following considerations. To determine the value of the steady-state short-circuit current in the conductor, it is necessary to measure the time of the closed state of the reed switch, therefore, when a short-circuit occurs, the reed switch must close and open. The time $t_{1}$ of the closed state of the reed switch cannot exceed $0.01 \mathrm{~s}$, we will designate it as the time $t_{h}$ of the measurement. After measuring $t_{1}$, the microprocessor performs mathematical operations, assignment and comparison operations. The number of operations in the algorithm does not exceed 50 , the microprocessor performs them in one cycle, which lasts no more than $0.001 \mathrm{~s}$, let us designate its time $t_{L}$ of the cycle execution. And the operation of the output relay remains, which for high-speed relays does not exceed $0.01 \mathrm{~s}$, we will designate as $t_{P}$. Thus, the performance is estimated by the formula

$$
t_{\text {ОТКл }}=t_{\text {И }}+t_{L}+t_{P}=0,021 \mathrm{~s} .
$$

The device on the reed switch and the MP allows transmitting in digital form (binary code) to the microprocessor protection a certain amount of current in the primary circuit. The presented measuring device in accordance with Figure 4 made it possible to implement a method for determining the value of the steady-state short-circuit current.

\section{Conclusion}

A reed switch located near the current conductor of an electrical installation and a microprocessor make it possible to determine the value of the steady-state short-circuit current in the primary circuit with an error $\leq 10 \%$ with its multiplicity $K \leq 80$. To do this, you need to measure time $t_{1}$ the closed state of the reed switch contacts and in the microprocessor determine the value $I_{m}$ current in the conductor from the formula $I_{m}=K_{\Pi P} \cdot I_{m K}=K_{\Pi P} \cdot \sum_{n=0}^{n} a n \cdot\left(t_{1}^{K}\right)^{n}$, obtained after approximation of the dependence $I_{m K}=f\left(t_{1}^{K}\right)$ taken in laboratory conditions using IC ( $L_{K}>>R, L_{K}$ - winding length, $R$ - loop radius). In the formula $I_{m K}$ - current in the inductor coil (IC); $t_{1}^{K}$ - the same time as $t_{1}$ (only when the reed switch is located in the IC); $K_{\Pi P}$ - conversion factor $I_{m}$ from the magnitude $I_{m K} ; n$-degree of approximating polynomial.

The developed device on a reed switch and a microprocessor implements a method for determining the value of the steady-state short-circuit current. When adding a program block for comparing a certain current value with a setting and an output relay, the device performs the functions of a current protection measuring device, which does not need information from a current transformer. The code of his program is presented. The performance is estimated at $21 \mathrm{~ms}$.

\section{Gratitude}

The authors express their gratitude to the Ministry of Education and Science of the Republic of Kazakhstan for funding scientific works The research was carried out within the framework of the project AP09562138 "Research of an innovative microprocessor-based resource-saving relay protection device" under the budget program 217 "Development of Science", subprogram 102 "Grant financing of scientific research at the expense of the republican budget". 


\section{Reference}

1. Chernobrovov, N.V., \& Semenov, V.A. (1998). Relay protection of energy systems: textbook. pos. for technical schools. NV Chernobrovov.

2. Sirota, I.M., \& Shurin, V.M. (1971). Filters of symmetrical components in circuits with remote sensors. Electrical Engineering, (11), 26-31.

3. Meerovich, E.A., Nazarov, L.A., Karabaev, G.H., \& Kokurkin, B.P. (1980). Measurement of currents of high voltage lines by its magnetic fields. Electrical Engineering, (7), 32-40.

4. Kazansky, V.E. (1988). Measuring current transducers in relay protection. M.: Energoatomizdat.

5. Kletzel, M. Ya., \& Musin, V. V. (1987). About construction on reed switches of protections of highvoltage installations without current transformers. Electrical Engineering, (4), 11-13.

6. Kozovic, L.A., \& Bishop, M.T. (2009, September). Modern relay protection with current sensors based on the Rogovsky coil. In Modern directions of development of relay protection systems and automation of power systems: Sat. report International. scientific and technical conf. Moscow (pp. 7-10).

7. Kletsel, M.Ya. (1991). Principles of construction and models of differential protections of electrical installations on reed switches. Electrical Engineering, (10), 47-50.

8. Kletsel, M.Ya., Alishev, Zh.R., Manukovsky, A.V., \& Musin, V.V. (1993). Properties of reed switches when using them in relay protection. Electrical Engineering, (9), 18-21.

9. Kletsel, M.Ya., \& Maishev, P.N. (2007). Features of construction on reed switches of differentialphase protections of transformers. Electrical Engineering, (12), 2-7.

10. Schoff, W. N. (1993). Reed switches and reed devices: Handbook. MEI Publishing House.

11. Karabanov, S.M., Meisels, R.M., \& Schoff, V.N. (2011). Magnetically controlled contacts (reed switches) and products based on them.

12. Meisels, R.M., Schoff, W.N. (1998). Reed switches. A look at the prospects of the direction. Electrical Engineering, 1, 20-25.

13. Kletsel, M.Ya., Neftisov, A.V., Maishev, P.N., \& Zhantlesova, A.B. (2014). Identification of the steadystate short-circuit current by means of reed switches. Electrical Engineering, 4, 28-34.

14.Zhantlesova, A.B., Kletsel, M.Y., Maishev, P.N., \& Neftisov, A.V. (2014). Characterizing a sustained short-circuit current with the use of reed relays. Russian Electrical Engineering, 85(4), 210-216.

15. Andreyeva, O., Neftissov, A., \& Mileiko, A. (2021, March). Method of diagnostics of the short-circuited rotor damage on point induction converters. In AIP Conference Proceedings (Vol. 2337, No. 1, p. 030001). AIP Publishing LLC.

16. Neftissov, A.V., Andreyeva, O.A., \& Sarinova, A.Z. (2021, March). Investigation of the properties of reed switches in devices for resource-saving relay protection of the electrical part of power plants. In AIP Conference Proceedings (Vol. 2337, No. 1, p. 030010). AIP Publishing LLC. 